\title{
Sphingosine-1-Phosphate: Boon and Bane for the Brain
}

\author{
Gerhild van Echten-Deckert ${ }^{\mathrm{a}} \quad$ Nadine Hagen-Euteneuer ${ }^{\mathrm{a}} \quad$ Ilker Karaca $^{\mathrm{b}}$ \\ Jochen Walter ${ }^{b}$
}

aLife and Medical Sciences (LIMES), Membrane Biology and Lipid Biochemistry Unit at the KekuléInstitute, University of Bonn, bepartment of Neurology, University of Bonn, Bonn, Germany

\section{Key Words}

Sphingosine-1-phosphate - S1P-lyase • Neurodegeneration • Amyloid beta • cis-4methylsphingosine • FTY720 (fingolimod) • Alzheimer's disease • Tau

\begin{abstract}
Sphingosine-1-phosphate (S1P), an evolutionary conserved bioactive lipid, is essential for brain development, but might also exert detrimental effects in terminally differentiated postmitotic neurons. Its concentration in the brain is tightly regulated by specific kinases and phosphatases, and mainly by the S1P degrading enzyme, S1P-lyase (S1PL). The role of S1P in neurons was initially studied in primary cultures by using structural analogues. During the last 3 years generation of a S1PL deficient mouse model substantially promoted our knowledge on the functional role of S1P metabolism in the brain, and its potential relation to neurodegenerative diseases. However, our understanding of the molecular mechanisms that underlie the physiological and pathophysiological actions of S1P in neurons remains rather scarce.

Copyright (C) 2014 S. Karger AG, Basel
\end{abstract}

\section{Introduction}

Sphingolipids are essential components of lipid bilayers conferring unique structural and signaling functions. Together with cholesterol they are main components of detergent resistant membrane microdomains, called lipid rafts [1]. Membrane dynamics and vesicular trafficking are tightly related to the interconversion of sphingolipids [2].

Complex glycosphingolipids, especially the sialic acid-containing gangliosides are particularly abundant and exhibit characteristic profiles in neuronal cells [3]. Vital functions

Gerhild van Echten-Deckert and Jochen Walter
Kekulé-Institute, Gerhard-Domagk-Str. 1, 53121 Bonn (Germany)

and Dept. of Neurology, University of Bonn

Sigmund-Freud-Str. 25, 53127 Bonn (Germany)

E-Mail g.echten.deckert@uni-bonn.de and E-Mail jochen.walter@ukb.uni-bonn.de 
including information flux and transduction occur along neuronal membranes. It is therefore not surprising that impaired sphingolipid metabolism is closely related to various neurological disorders. Metabolic intermediates of these lipids, notably sphingosine, ceramide, and S1P, are bioactive molecules and regulate numerous cellular signalling pathways [4]. S1P can act extracellularly as a ligand for a family of five specific G protein coupled receptors (S1PRs1-5) or inside of cells as a second messenger [5]. In line with the involvement in complex cellular processes, S1P regulates cell survival and differentiation, motility and cytoskeleton dynamics as well as cell specific roles in immunity and angiogenesis $[6,7]$.

S1P signalling via specific receptors is critical during development. Deficiency in S1PR1 leads to embryonic lethality due to impaired vascular maturation and severe haemorrhage [8]. S1P is, however, not only essential for vascularisation and organ development in the periphery, but also for development of the brain [9]. In addition S1P is an important mediator of nociception $[10,11]$. Besides the signalling via specific receptors experimental evidence also suggests receptor-independent functions of S1P in calcium homeostasis [12], cellular growth [13], inhibition of apoptosis [14, 15], histone modifications [16], and nuclear factor$\kappa \mathrm{B}$ signalling [17].

In peripheral tissues, S1P mainly exerts pro-survival and proliferative effects [13]. However, increased S1P levels could also induce death of terminally differentiated postmitotic neurons [18]. Recent evidence also suggests a role of S1P in Alzheimer's disease (AD) [19-22]. Intriguingly, S1P in murine neurons stimulates beta-site APP cleaving enzyme (BACE1) that catalyzes the rate-limiting step in the formation of the amyloid peptide (A $\beta$ ), a major component of the characteristic extracellular plaques in the AD brain [23].

Here we give an overview on experimental data that argue in favour of S1P as a potential molecular link connecting impaired lipid metabolism and neurodegeneration.

\section{S1P metabolism}

S1P is a degradation product of ceramide, the central molecule of sphingolipid metabolism (Fig.1). A family of ceramidases, which differ in their $\mathrm{pH}$ optimum and subcellular localization, hydrolyses ceramide to sphingosine, which is either phosphorylated to $\mathrm{S} 1 \mathrm{P}$ or reutilised for ceramide formation via a salvage pathway [3]. Interestingly, acid ceramidase is a major glycoprotein in human brain and mainly expressed in neurons [24]. Even more interestingly, the expression and activity of this enzyme were found to be elevated in Alzheimer's disease brain and to colocalize with neurofibrillary tangles, suggesting an involvement in neuronal degeneration during the pathogenesis of AD [24]. Sphingosine can be phosphorylated by two sphingosine kinase (SK) isoforms, SK1 and SK2 [25, 26]. The two enzymes differ not only in their kinetic properties and subcellular localizations, but also in their developmental- and tissue-specific expression. While the cytosolic SK1 is activated upon recruitment to the plasma membrane, the constitutively membrane associated SK2 is active in the ER and nucleus. There are contradictory reports on the expression of the two isoforms in the brain. Although SK1 was reported to positively regulate glutamate secretion in embryonic rat hippocampal neurons [27], there are studies with human as well as with rodent brain that identified exclusively SK2, suggesting that this isoform is particularly important in the central nervous system $[28,29]$. Two very recent studies, however, highlight the importance of SK1 in AD pathogenesis in human brain [21, 22]. S1P can be dephosphorylated to sphingosine by specific S1P phosphatases (SPP1 and SPP2) and less specific lipid phosphate phosphatases (LPPs) [30]. The interplay of SKs and SPPs allows a fine-tuned regulation of S1P and sphingosine concentrations. In addition, S1P can undergo irreversible cleavage by S1PL (Fig. 1) [31]. S1PL cleaves S1P at the C2-3 carbon bond yielding a long-chain aldehyde and phosphoethanolamine, thus sitting at the junction between sphingolipid and phospholipid metabolism [32]. An N-terminal hydrophobic domain anchors this pyridoxal 5'-phosphate-dependent enzyme to the ER membrane with its active site facing the cytosol. Thus phosphatases enable cells to recycle the sphingoid 
scaffold in a ceramide salvage pathway, whereas S1PL activity results in a net reduction of sphingolipid content, representing the only exit point for sphingolipid degradation.

\section{S1P - not always a survival signal}

In most cell types S1P and its metabolic precursor ceramide exert antagonistic effects on cell survival. Due to its tissue protective properties S1P emerged primarily as a survival signal whereas ceramide mediates cellular stress and promotes cell death $[33,34]$. The observation that S1P can rescue cells from ceramide induced apoptosis [14, 35], led to the ceramide/S1P rheostat model, which assumes that the dynamic balance of intracellular levels of these two bioactive sphingolipids is critical for cellular fate decisions [36]. However, elevated levels of endogenous sphingoid long-chain base phosphates, structurally resembling S1P caused cell death in yeast [37]. In addition, S1P treatment induced apoptosis in mammalian cells including HepG2 [38] and hepatic myofibroblasts [39]. In neuronal cells the grade of differentiation appears to be important for the effect of S1P on cell survival. While S1P stimulates proliferation in neural progenitor cells [40], it induces apoptosis in differentiated hippocampal neurons [41]. As shown in Fig. 1, the metabolism of the two antagonistic bioactive sphingolipids, ceramide and S1P, is closely interconnected. This might hamper the study of their individual signalling function. Accordingly, a recent study in HeLa cells with different pharmacological modulators suggests that not ceramide itself, but rather downstream metabolites of ceramide such as S1P and especially hexadecenal promote cell death [42].

\section{Neurotoxicity of S1P and of structural analogues}

Early studies with the synthetic sphingosine analogue cis-4-methylsphingosine (cimes) carrying a cis-instead of the naturally occuring trans- double bond and an additional methyl group on carbon atom C4 [43] showed pro-mitogenic effect of its short-lived physiological counterpart S1P in quiescent Swiss 3T3 fibroblasts [44]. However, it induced apoptosis in terminally differentiated post-mitotic neurons [45]. Cimes is rapidly taken up by cells, but unlike the physiological archetype it was not $\mathrm{N}$-acylated to the respective ceramide. Rather it is exclusively phosphorylated to the corresponding cis-4-methylsphingosine-phosphate (cimesP) [46]. In contrast to S1P, cimesP is not cleaved by S1PL, and thus, accumulates in a time-dependent and cell type-specific manner. Consequently, the use of cimes as a synthetic pro-drug that is just phosphorylated to the cleavage resistant S1P-analogue cimesP should enable to differentiate between the potential role of ceramide and S1P in cell fate decisions.

The apoptotic effect of cimesP is mediated by a caspase-dependent and p38 MAPKtriggered pathway and involves an aberrant reactivation of the cell cycle [45]. Interestingly, S1P affected similar pathways, but due to its fast intracellular turn-over in a more transient and less pronounced manner, likely not reaching higher critical concentrations for directing neurons into apoptosis. However, in S1PL-deficient neurons, where degradation of S1P is inhibited (Fig. 1), the levels of accumulated S1P correlated with neuronal apoptosis [18]. Importantly, only S1P generated by SK2 induced neuronal apoptosis, thus highlighting the significance of the subcellular site for the physiological impact of a bioactive compound [18]. SK2 was also reported to be up-regulated in brains of patients with sporadic Alzheimer's disease [23]. While SK1 is highly specific for the phosphorylation of sphingosine, SK2 has broader substrate specificity and also catalyzes phosphorylation of cimes [18]. Accordingly, cimes failed to induce death of SK2-deficient neurons, but was toxic in wild type and SK1deficient neurons [19]. Notably, the immunosuppressant FTY720 (fingolimod) exerted a similar neurotoxic effect as cimes (Fig. 2). This was not surprising given the fact that FTY720 is a natural sphingosine analogue pro-drug functionally activated by SK2-catalysed phosphorylation [47]. Also phosphorylation of AAL(R), a structural analogue of FTY720 by 
Fig. 1. Scheme of sphingolipid metabolism. Ceramide is formed either de novo starting from serine and palmitoylCoA or by hydrolysis of sphingomyelin or glycosphingolipids (GSL) including gangliosides. Alternatively, ceramide can be generated by recycling of its degradation product sphingosine. Ceramide is then further metabolized to more complex sphingolipids including sphingomyelin and GSL from which gangliosides are particularly abundant in neurons. Sphingosine-1-phosphate (S1P) is generated by phosphorylation of sphingosine by sphingosine kinases (SK) of which SK2 isoform predominates in the brain. It is either cleaved by S1PL into common cellular metabolites or dephosphorylated back to sphingosine by S1P-phosphatases (SPP). CS, ceramide synthase; CDase, ceramidases, from which the acid isoform prevails in the brain; SPT, serine palmitoyltransferase.

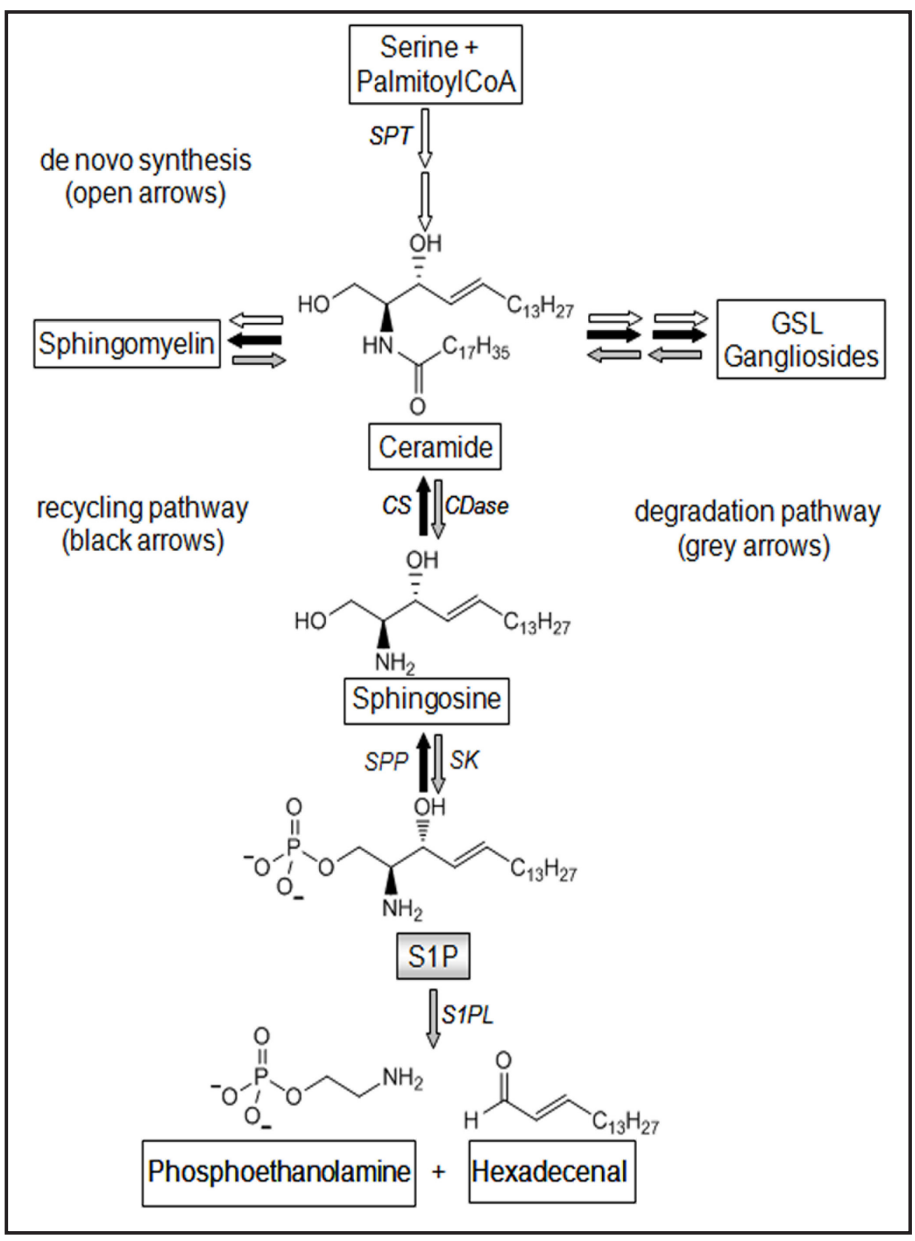

SK2 was shown to be essential for its potential to induce apoptosis in mouse and human lymphocytes [48]. Similarly, cimes induced apoptosis in B104 neuroblastoma cells [49]. By contrast, direct exposure of mouse embryonic cortical neurons to FTY720-phosphate (1 - 100 $\mathrm{pM}$ ) protected them against $\mathrm{A} \beta$ toxicity [50]. This neuroprotective effect was accompanied by an enhanced expression of brain-derived neurotrophic factor. Obviously, phosphorylated FTY720 in picomolar concentrations is neuroprotective, but when accumulating above a certain threshold - possibly in vulnerable subcellular compartments - might become neurotoxic.

Further studies with S1PL-deficient neurons and with cimes established that downstream neurotoxic signalling of S1P is promoted by the ER-specific proteases caspase-12 and calpain without involvement of mitochondria [19]. The activation of these proteases was dependent on elevated intracellular calcium levels that could result from S1P triggered release from ER stores [51]. Thus, S1P-dependent neurotoxicity involves similar pathways as shown for that triggered by Alzheimer associated A $\beta$-peptide [19]. Treatment of neurons with extracellular $A \beta$ also activated caspase- 12 by disruption of the calcium homeostasis in the ER, independent on membrane- or mitochondria targeted apoptotic signals [52]. Furthermore, $A \beta$ can also induce an aberrant reactivation of cell cycle events and activation of CDK5 $[53,54]$. It is important to note that calpain activation has been described in several neuronal pathologies, many of them including also CDK5 deregulation caused by calpain mediated cleavage of the CDK5 regulatory subunit p35 [55, 56]. CDK5 was suggested to link $A \beta$-peptide containing senile plaques with neurofibrillary tangles composed of hyperphosphorylated tau [57]. Accordingly, S1P-induced neurotoxocity is accompanied by CDK5 activation and hyperphosphorylation of tau [19]. 


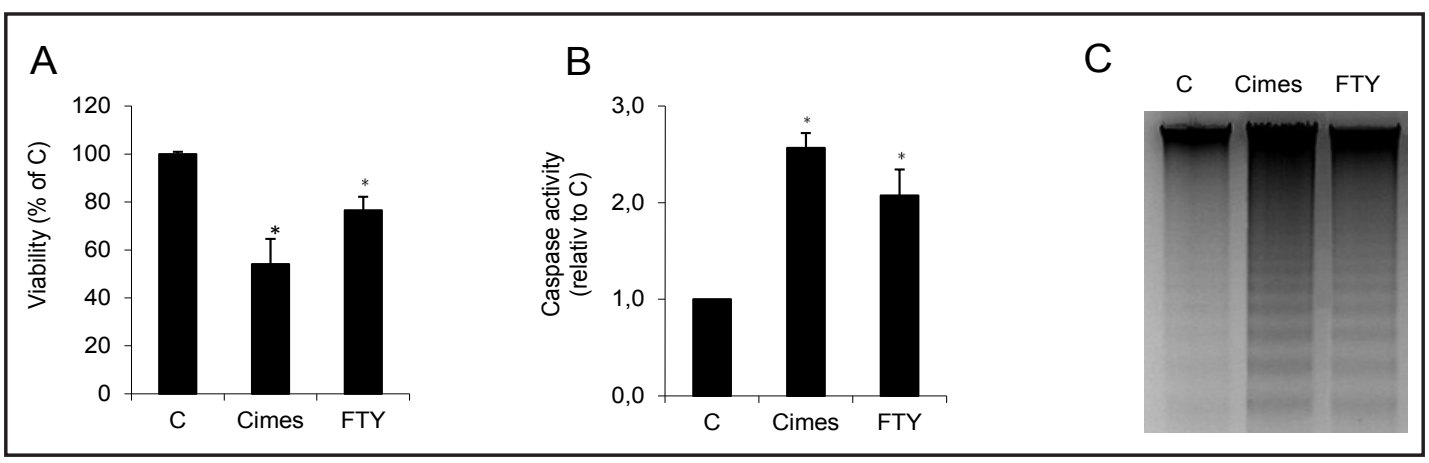

Fig. 2. Fingolimod (FTY720) and cimes induce apoptosis in post-mitotic neurons. Cerebellar neurons were incubated with vehicle (controls, C), or with $10 \mu \mathrm{M}$ of cimes or fingolimod. After $24 \mathrm{~h}$ viability (A), relative effector-caspase activity (B) as well as genomic DNA (C) were assessed as described previously [18]. *significantly different from controls $(\mathrm{p}<0,05)$.

Fig. 3. Generation of $A \beta$ by proteolytic processing of the APP. APP is a type I membrane protein with a large ectodomain, a single transmembrane domain, and a small cytoplasmic tail. The $A \beta$ domain starts in the ectodomain and extends into the transmembrane region. $A \beta$ generation is initiated by cleavage of APP in the ectodomain by $\beta$-secretase. The resulting C-terminal fragment (CTF) is then processed by $\gamma$-secretase within the transmembrane region leading to secretion of $A \beta$ into the extracellular milieu and release of the APP intracellular domain into the cytosol (AICD).

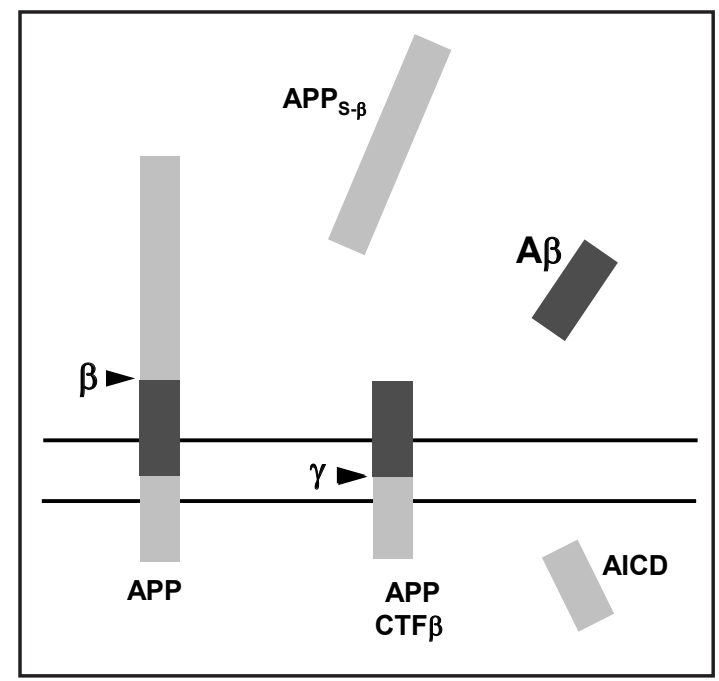

\section{S1P - a potential mediator in the pathogenesis of Alzheimer's disease}

Alzheimer's disease is characterized by the progressive accumulation of $A \beta$ in form of extracellular plaques and intraneuronal aggregates of the microtubuli-associated tau protein [58]. Strong evidence from genetics, biochemistry and cell biology supports a critical role of $A \beta$ in the initiation and progression of $\operatorname{AD}[59,60] . A \beta$ derives by proteolytic processing of the amyloid precursor protein (APP), involving proteases called $\beta$ - and $\gamma$-secretase (Fig. 3) $[61,62]$. APP and the secretases are integral membrane proteins, and numerous studies have demonstrated a role of cholesterol in the proteolytic processing of APP and the generation of $A \beta$ [63-66]. However, the exact molecular mechanisms and the relevance of cholesterol in $\mathrm{AD}$ pathogenesis is still under debate [63-66]. The role of lipid homeostasis in the brain, particularly that of membrane lipids, in AD pathogenesis has been recognized and considered in multitudinous studies $[67,68]$.

Notably, neuronal membranes contain a highly specific and characteristic pattern of complex sphingolipids. It is therefore not surprising that neuronal function and survival is dependent on the metabolism of these lipids. As depicted above, growing evidence indicates that S1P, a bioactive catabolic intermediate of all sphingolipids might represent a potential link between ganglioside metabolism and neurodegeneration. Neuronal levels of S1P are tightly regulated at very low concentrations in the picomolar range $[18,69]$. A direct role of $\mathrm{S} 1 \mathrm{P}$ in neuronal $\mathrm{A} \beta$ generation has been reported recently [23]. The inhibition of SKs and thus the generation of $\mathrm{S} 1 \mathrm{P}$ decreased $\mathrm{A} \beta$ production in primary neuronal cultures and in 


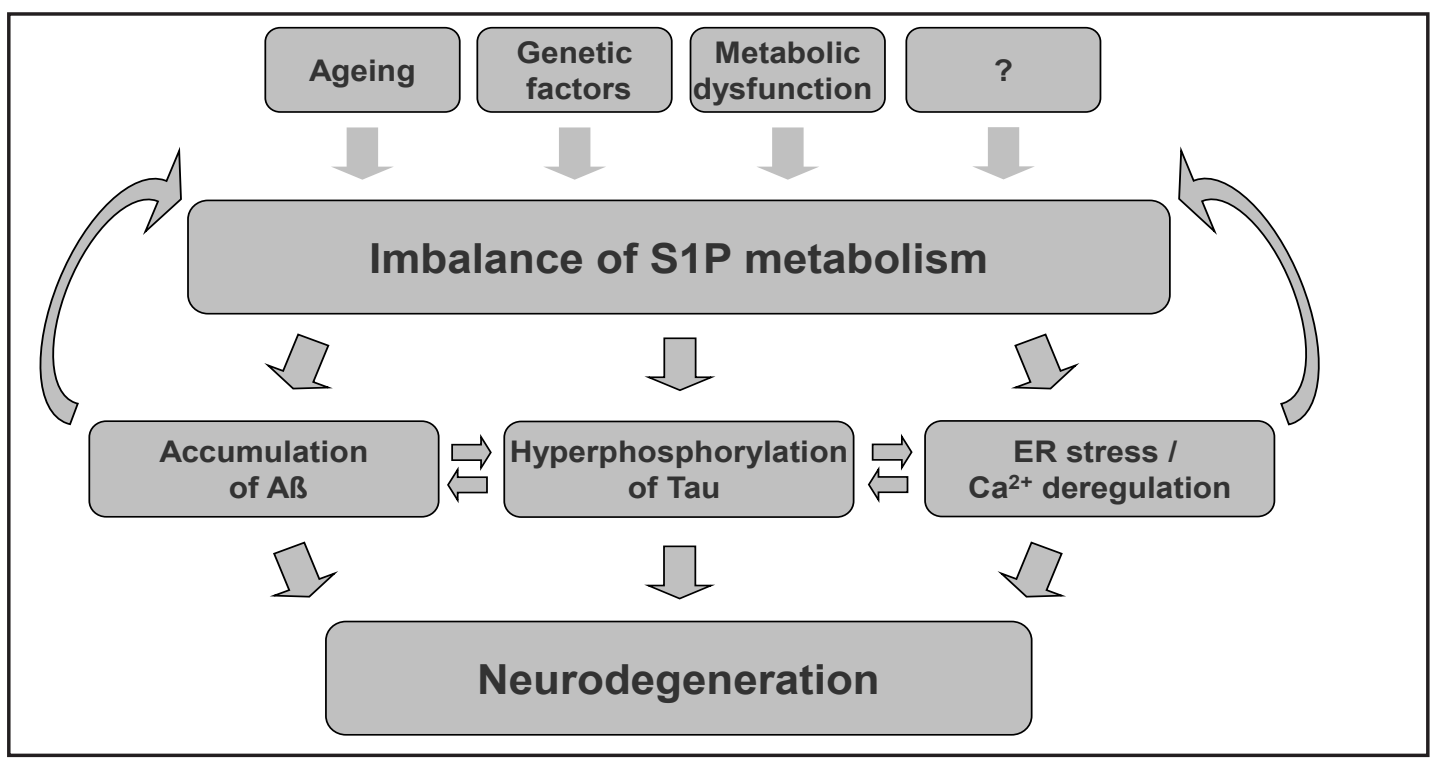

Fig. 4. Hypothetical model for the role of S1P in neurodegeneration. Alterations in S1P levels that might be caused by different factors including ageing, genetics and metabolic changes are associated with hyperphosphorylation of tau, increased generation of $A \beta$, and deregulation of $\mathrm{Ca}^{2+}$ homeostasis eventually leading to neurodegeneration.

brains of mice. Further, it has been shown that S1P stimulates the $\beta$-secretase BACE1 by direct interaction with the enzyme [23]. Interestingly, primary cultured neurons of S1PLdeficient mice revealed a striking correlation of elevated S1P concentration and neuronal death. The S1P-induced neurotoxicity was found to be mediated by a calcium/calpain/CDK5 promoted mechanism. Moreover, S1PL deficiency also induced hyperphosphorylation of tau [19]. In addition, S1PL knock-out cells showed strong accumulation of APP and potentially amyloidogenic APP C-terminal fragments, which was associated with impaired lysosomal degradation [70]. Besides, we also observed increased generation of A $\beta$ in S1PL-deficient cells [70]. Together, the combined data from pharmacologic and genetic models suggest that $\mathrm{S} 1 \mathrm{P}$ could modulate both $\mathrm{A} \beta$ generation and toxicity. Of interest, in the central nervous system S1P levels were found to be highest in spinal cord and brainstem, moderate in cerebellum and lowest in cortex [71]. The distribution of S1P correlated positively with S1PL expression, suggesting an up-regulation of this enzyme in areas with high S1P levels [72]. Apparently, brain regions most susceptible to neurodegeneration have low S1P content. Based on our finding that neurons with most abundant S1PL expression are those that degenerate first in S1PL-deficient brains [19], and on the fact that S1PL is the major regulator of S1P levels [73], one could speculate that brain regions with lowest S1P content are those with most abundant S1PL activity, and are therefore particularly sensitive to an impaired degradation of S1P by S1PL. Thus, alterations in the levels of S1P, sphingosine and probably other lipids caused by different factors, could affect the metabolism of both characteristic proteins in $\mathrm{AD}, \mathrm{A} \beta$ and tau (Fig. 4). Notably, the effect of S1PL deficiency on sphingolipid metabolism in neurons and cholesterol levels in the brain was rather slight when compared with that in liver and serum $[69,73]$. Thus, no significant changes of the content of ceramide, sphingomyelin and of glycosphingolipids in neurons could be detected [69]. This might be explained by the substantially decreased de novo formation of sphingolipids and a concurrent increase in the recycling pathway in these neurons [69].

Two very recent reports also highlight the importance of S1P in AD pathology, but suggest that rather a reduction than an increase of S1P in the brain is associated with neurodegeneration [21, 22]. Interestingly, the region-specific decline of the S1P/sphingosine ratio in the hippocampus and temporal cortex during the course of $\mathrm{AD}$ pathogenesis was 
correlated primarily with a loss of SK1 activity [21]. In addition, expression of SK1 was reduced whereas that of S1PL was increased in the entorhinal cortex in human AD brains suggesting a negative correlation of $\mathrm{A} \beta$ deposits and $\mathrm{S} 1 \mathrm{P}$ content in $\mathrm{AD}$ relevant brain regions [22].

Concordantly, FTY720 reduced A $\beta$ release in cultured neurons, apparently independent of known downstream signaling pathways of S1PRs [74]. FTY720 was also found to attenuate $\mathrm{A} \beta$-induced cognitive impairment and neuronal damage in the hippocampus of rats [75]. The neuroprotective effect of FTY720 was associated with altered gene transcription of mitogen activated protein kinases (MAPKs) and some inflammatory markers [76]. Thus, FTY720 might not only affect $A \beta$ generation, but also the neruoinflammatory process during the pathogenesis of AD.

\section{Conclusions and Outlook}

The inhibition of S1P degradation tightly correlates with neuronal death in vitro and in vivo. Interestingly, S1PL deficiency also induces hyperphosphorylation of tau [19], and altered metabolism of APP resulting in increased generation of $A \beta$ [70]. Thus, a genetic model of impaired S1P metabolism reveals certain disease specific alterations of the two major proteins involved in AD. This raises intriguing questions on the pathophysiological role of S1P metabolism during AD pathogenesis: Could age-dependent alterations in S1P/ sphingosine metabolism trigger or at least modulate pathological pathways leading to the accumulation of $A \beta$, hyperphosphorylation of tau and ultimately cell death in AD? Could $\mathrm{S} 1 \mathrm{P}$ and related metabolites and enzymes be further explored for AD therapy, prevention or biomarker identification? A recent study reports on reduced expression of SK1 and enhanced expression of S1PL suggesting a deregulated S1P signalling in AD brains [22]. Thus, it will be important to further dissect the molecular mechanisms that underlie the different effects of $\mathrm{S} 1 \mathrm{P}$ metabolism in AD pathogenesis.

\section{Disclosure Statement}

The authors declare no conflict of interest in writing this article.

\section{Acknowledgements}

The laboratories of GvED and JW are supported by the priority program 1267 of the Deutsche Forschungsgemeinschaft (DFG; grants EC-118/6-1 to GvED, WA1477/8-1 to JW,), the collaborative research center 645 (TP A7 to JW), and the clinical research group KF0177 (grant WA1477/4-2 to JW).

\section{References}

1 Simons K, Gerl MJ: Revitalizing membrane rafts: New tools and insights. Nat Rev Mol Cell Biol 2010;11:688-699.

-2 Zhang Y, Li X, Becker KA, Gulbins E: Ceramide-enriched membrane domains--structure and function. Biochim Biophys Acta 2009;1788:178-183.

-3 van Echten-Deckert G, Herget T: Sphingolipid metabolism in neural cells. Biochim Biophys Acta 2006;1758:1978-1994.

-4 Hannun YA, Obeid LM: Principles of bioactive lipid signalling: Lessons from sphingolipids. Nat Rev Mol Cell Biol 2008;9:139-150.

5 Spiegel S, Milstien S: Sphingosine-1-phosphate: Signaling inside and out. FEBS Lett 2000;476:55-57.

6 Spiegel S, Milstien S: Sphingosine-1-phosphate: An enigmatic signalling lipid. Nat Rev Mol Cell Biol 2003;4:397-407.

7 Saba JD, Hla T: Point-counterpoint of sphingosine 1-phosphate metabolism. Circ Res 2004;94:724-734. 
van Echten-Deckert/Hagen-Euteneuer/Karaca/Walter: S1P in the Brain

8 Liu Y, Wada R, Yamashita T, Mi Y, Deng CX, Hobson JP, Rosenfeldt HM, Nava VE, Chae SS, Lee MJ, Liu CH, Hla T, Spiegel S, Proia RL: Edg-1, the G protein-coupled receptor for sphingosine-1-phosphate, is essential for vascular maturation. J Clin Invest 2000;106:951-961.

-9 Mizugishi K, Yamashita T, Olivera A, Miller GF, Spiegel S, Proia RL: Essential role for sphingosine kinases in neural and vascular development. Mol Cell Biol 2005;25:11113-11121.

$>10$ Inoue M, Rashid MH, Fujita R, Contos JJ, Chun J, Ueda H: Initiation of neuropathic pain requires lysophosphatidic acid receptor signaling. Nat Med 2004;10:712-718.

11 Doyle T, Chen Z, Obeid LM, Salvemini D: Sphingosine-1-phosphate acting via the S1P(1) receptor is a downstream signaling pathway in ceramide-induced hyperalgesia. Neurosci Lett 2011;499:4-8.

12 Meyer zu Heringdorf D, Liliom K, Schaefer M, Danneberg K, Jaggar JH, Tigyi G, Jakobs KH: Photolysis of intracellular caged sphingosine-1-phosphate causes $\mathrm{Ca}^{2+}$ mobilization independently of G-protein-coupled receptors. FEBS Lett 2003;554:443-449.

13 Olivera A, Spiegel S: Sphingosine-1-phosphate as second messenger in cell proliferation induced by PDGF and FCS mitogens. Nature 1993;365:557-560.

14 Cuvillier O, Pirianov G, Kleuser B, Vanek PG, Coso OA, Gutkind S, Spiegel S: Suppression of ceramidemediated programmed cell death by sphingosine-1-phosphate. Nature 1996;381:800-803.

15 Olivera A, Rosenfeldt HM, Bektas M, Wang F, Ishii I, Chun J, Milstien S, Spiegel S: Sphingosine kinase type 1 induces G12/13-mediated stress fiber formation, yet promotes growth and survival independent of G protein-coupled receptors. J Biol Chem 2003;278:46452-46460.

16 Hait NC, Allegood J, Maceyka M, Strub GM, Harikumar KB, Singh SK, Luo C, Marmorstein R, Kordula T, Milstien S, Spiegel S: Regulation of histone acetylation in the nucleus by sphingosine-1-phosphate. Science 2009;325:1254-1257.

17 Bagdanoff JT, Donoviel MS, Nouraldeen A, Tarver J, Fu Q Carlsen M, Jessop TC, Zhang H, Hazelwood J, Nguyen H, Baugh SD, Gardyan M, Terranova KM, Barbosa J, Yan J, Bednarz M, Layek S, Courtney LF, Taylor J, Digeorge-Foushee AM, Gopinathan S, Bruce D, Smith T, Moran L, O'Neill E, Kramer J, Lai Z, Kimball SD, Liu Q, Sun W, Yu S, Swaffield J, Wilson A, Main A, Carson KG, Oravecz T, Augeri DJ: Inhibition of sphingosine-1phosphate lyase for the treatment of autoimmune disorders. J Med Chem 2009;52:3941-3953.

18 Hagen N, Van Veldhoven PP, Proia RL, Park H, Merrill AH Jr, van Echten-Deckert G: Subcellular origin of sphingosine 1-phosphate is essential for its toxic effect in lyase-deficient neurons. J Biol Chem 2009;284:11346-11353.

19 Hagen N, Hans M, Hartmann D, Swandulla D, van Echten-Deckert G: Sphingosine-1-phosphate links glycosphingolipid metabolism to neurodegeneration via a calpain-mediated mechanism. Cell Death Differ 2011;18:1356-1365.

20 van Echten-Deckert G, Walter J: Sphingolipids: Critical players in Alzheimer's disease. Prog Lipid Res 2012;51:378-393.

21 Couttas TA, Kain N, Daniels B, Lim XY, Shepherd C, Kril J, Pickford R, Li H, Garner B, Don AS: Loss of the neuroprotective factor sphingosine 1-phosphate early in Alzheimer's disease pathogenesis. Acta Neuropathol Commun 2014;2:9.

22 Ceccom J, Loukh N, Lauwers-Cances V, Touriol C, Nicaise Y, Gentil C, Uro-Coste E, Pitson S, Maurage CA, Duyckaerts C, Cuvillier O, Delisle MB: Reduced sphingosine kinase-1 and enhanced sphingosine 1-phosphate lyase expression demonstrate deregulated sphingosine 1-phosphate signaling in Alzheimer's disease. Acta Neuropathol Commun 2014;2:12.

23 Takasugi N, Sasaki T, Suzuki K, Osawa S, Isshiki H, Hori Y, Shimada N, Higo T, Yokoshima S, Fukuyama T, Lee VM, Trojanowski JQ, Tomita T, Iwatsubo T: Bace1 activity is modulated by cell-associated sphingosine-1phosphate. J Neurosci 2011;31:6850-6857.

24 Huang Y, Tanimukai H, Liu F, Iqbal K, Grundke-Iqbal I, Gong CX: Elevation of the level and activity of acid ceramidase in Alzheimer's disease brain. Eur J Neurosci 2004;20:3489-3497.

-25 Kohama T, Olivera A, Edsall L, Nagiec MM, Dickson R, Spiegel S: Molecular cloning and functional characterization of murine sphingosine kinase. J Biol Chem 1998;273:23722-23728.

26 Liu H, Sugiura M, Nava VE, Edsall LC, Kono K, Poulton S, Milstien S, Kohama T, Spiegel S: Molecular cloning and functional characterization of a novel mammalian sphingosine kinase type 2 isoform. J Biol Chem 2000;275:19513-19520.

27 Kajimoto T, Okada T, Yu H, Goparaju SK, Jahangeer S, Nakamura S: Involvement of sphingosine-1-phosphate in glutamate secretion in hippocampal neurons. Mol Cell Biol 2007;27:3429-3440. 
van Echten-Deckert/Hagen-Euteneuer/Karaca/Walter: S1P in the Brain

28 Katsel P, Li C, Haroutunian V: Gene expression alterations in the sphingolipid metabolism pathways during progression of dementia and Alzheimer's disease: A shift toward ceramide accumulation at the earliest recognizable stages of Alzheimer's disease? Neurochem Res 2007;32:845-856.

29 Blondeau N, Lai Y, Tyndall S, Popolo M, Topalkara K, Pru JK, Zhang L, Kim H, Liao JK, Ding K, Waeber C: Distribution of sphingosine kinase activity and mRNA in rodent brain. J Neurochem 2007;103:509-517.

30 Brindley DN: Lipid phosphate phosphatases and related proteins: Signaling functions in development, cell division, and cancer. J Cell Biochem 2004;92:900-912.

-31 Aguilar A, Saba JD: Truth and consequences of sphingosine-1-phosphate lyase. Adv Biol Regul 2012;52:1730 .

32 Van Veldhoven PP: Sphingosine-1-phosphate lyase. Methods Enzymol 2000;311:244-254.

33 Hannun YA, Obeid LM: The ceramide-centric universe of lipid-mediated cell regulation: Stress encounters of the lipid kind. J Biol Chem 2002;277:25847-25850.

-34 Gulbins E, Kolesnick R: Raft ceramide in molecular medicine. Oncogene 2003;22:7070-7077.

-35 Morita Y, Perez GI, Paris F, Miranda SR, Ehleiter D, Haimovitz-Friedman A, Fuks Z, Xie Z, Reed JC, Schuchman $\mathrm{EH}$, Kolesnick RN, Tilly JL: Oocyte apoptosis is suppressed by disruption of the acid sphingomyelinase gene or by sphingosine-1-phosphate therapy. Nat Med 2000;6:1109-1114.

-36 Maceyka M, Payne SG, Milstien S, Spiegel S: Sphingosine kinase, sphingosine-1-phosphate, and apoptosis. Biochim Biophys Acta 2002;1585:193-201.

-37 Zhang X, Skrzypek MS, Lester RL, Dickson RC: Elevation of endogenous sphingolipid long-chain base phosphates kills saccharomyces cerevisiae cells. Curr Genet 2001;40:221-233.

-38 Hung WC, Chuang LY: Induction of apoptosis by sphingosine-1-phosphate in human hepatoma cells is associated with enhanced expression of bax gene product. Biochem Biophys Res Commun 1996;229:11-15.

39 Davaille J, Li L, Mallat A, Lotersztajn S: Sphingosine 1-phosphate triggers both apoptotic and survival signals for human hepatic myofibroblasts. J Biol Chem 2002;277:37323-37330.

40 Harada J, Foley M, Moskowitz MA, Waeber C: Sphingosine-1-phosphate induces proliferation and morphological changes of neural progenitor cells. J Neurochem 2004;88:1026-1039.

-41 Moore AN, Kampfl AW, Zhao X, Hayes RL, Dash PK: Sphingosine-1-phosphate induces apoptosis of cultured hippocampal neurons that requires protein phosphatases and activator protein-1 complexes. Neuroscience 1999;94:405-415.

42 Chipuk JE, McStay GP, Bharti A, Kuwana T, Clarke CJ, Siskind LJ, Obeid LM, Green DR: Sphingolipid metabolism cooperates with BAK and BAX to promote the mitochondrial pathway of apoptosis. Cell 2012;148:988-1000.

43 Bär T, Kratzer B, Wild R, Sandhoff K, Schmidt RR: Synthesis of methyl-branched sphingosines. Liebigs Ann Chem 1993:419-426.

44 van Echten-Deckert G, Schick A, Heinemann T, Schnieders B: Phosphorylated cis-4-methylsphingosine mimics the mitogenic effect of sphingosine-1-phosphate in Swiss 3 T3 fibroblasts. J Biol Chem 1998;273:23585-23589.

45 Naetzker S, Hagen N, Echten-Deckert G: Activation of p38 mitogen-activated protein kinase and partial reactivation of the cell cycle by cis-4-methylsphingosine direct postmitotic neurons towards apoptosis. Genes Cells 2006;11:269-279.

46 van Echten-Deckert G, Zschoche A, Bar T, Schmidt RR, Raths A, Heinemann T, Sandhoff K: Cis-4methylsphingosine decreases sphingolipid biosynthesis by specifically interfering with serine palmitoyltransferase activity in primary cultured neurons. J Biol Chem 1997;272:15825-15833.

-47 Allende ML, Sasaki T, Kawai H, Olivera A, Mi Y, van Echten-Deckert G, Hajdu R, Rosenbach M, Keohane CA, Mandala S, Spiegel S, Proia RL: Mice deficient in sphingosine kinase 1 are rendered lymphopenic by FTY720. J Biol Chem 2004;279:52487-52492.

-48 Don AS, Martinez-Lamenca C, Webb WR, Proia RL, Roberts E, Rosen H: Essential requirement for sphingosine kinase 2 in a sphingolipid apoptosis pathway activated by FTY720 analogues. J Biol Chem 2007;282:15833-15842.

49 Natzker S, Heinemann T, Figueroa-Perez S, Schnieders B, Schmidt RR, Sandhoff K, van Echten-Deckert G: Cis-4-methylsphingosine phosphate induces apoptosis in neuroblastoma cells by opposite effects on p38 and ERK mitogen-activated protein kinases. Biol Chem 2002;383:1885-1894.

50 Doi Y, Takeuchi H, Horiuchi H, Hanyu T, Kawanokuchi J, Jin S, Parajuli B, Sonobe Y, Mizuno T, Suzumura A: Fingolimod phosphate attenuates oligomeric amyloid beta-induced neurotoxicity via increased brainderived neurotrophic factor expression in neurons. PLoS One 2013;8:e61988. 
van Echten-Deckert/Hagen-Euteneuer/Karaca/Walter: S1P in the Brain

51 Ghosh TK, Bian J, Gill DL: Sphingosine 1-phosphate generated in the endoplasmic reticulum membrane activates release of stored calcium. J Biol Chem 1994;269:22628-22635.

52 Nakagawa T, Zhu H, Morishima N, Li E, Xu J, Yankner BA, Yuan J: Caspase-12 mediates endoplasmicreticulum-specific apoptosis and cytotoxicity by amyloid-beta. Nature 2000;403:98-103.

-53 Lopes JP, Oliveira CR, Agostinho P: Neurodegeneration in an abeta-induced model of Alzheimer's disease: The role of CDK5. Aging Cell 2010;9:64-77.

54 Lopes JP, Oliveira CR, Agostinho P: CDK5 acts as a mediator of neuronal cell cycle re-entry triggered by amyloid-beta and prion peptides. Cell Cycle 2009;8:97-104.

55 Patrick GN, Zukerberg L, Nikolic M, de la Monte S, Dikkes P, Tsai LH: Conversion of p35 to p25 deregulates CDK5 activity and promotes neurodegeneration. Nature 1999;402:615-622.

56 Dhavan R, Tsai LH: A decade of CDK5. Nat Rev Mol Cell Biol 2001;2:749-759.

57 Lee MS, Tsai LH: Cdk5: One of the links between senile plaques and neurofibrillary tangles? J Alzheimers Dis 2003;5:127-137.

58 Selkoe D, Mandelkow E, Holtzman D: Deciphering Alzheimer disease. Cold Spring Harb Perspect Med 2012;2:a011460.

59 St George-Hyslop PH, Petit A: Molecular biology and genetics of Alzheimer's disease. C R Biol 2005;328:119-130.

60 Tanzi RE: The genetics of Alzheimer disease. Cold Spring Harb Perspect Med 2012;2: pii: a006296.

61 De Strooper B, Vassar R, Golde T: The secretases: Enzymes with therapeutic potential in Alzheimer disease. Nat Rev Neurol 2010;6:99-107.

62 Haass C, Kaether C, Thinakaran G, Sisodia S: Trafficking and proteolytic processing of APP. Cold Spring Harb Perspect Med 2012;2:a006270.

63 Hartmann T, Kuchenbecker J, Grimm MO: Alzheimer's disease: The lipid connection. J Neurochem 2007;103:S159-170.

64 Walter J: Gamma-secretase, apolipoprotein E and cellular cholesterol metabolism. Curr Alzheimer Res 2012;9:189-199.

65 Puglielli L, Tanzi RE, Kovacs DM: Alzheimer's disease: The cholesterol connection. Nat Neurosci 2003;6:345-351.

66 Wood WG, Li L, Muller WE, Eckert GP: Cholesterol as a causative factor in Alzheimer's disease: A debatable hypothesis. J Neurochem 2014;129:559-572.

67 Lane RM, Farlow MR: Lipid homeostasis and apolipoprotein E in the development and progression of Alzheimer's disease. J Lipid Res 2005;46:949-968.

68 Walter J, van Echten-Deckert G: Cross-talk of membrane lipids and Alzheimer-related proteins. Mol Neurodegener 2013;8:34.

69 Hagen-Euteneuer N, Lutjohann D, Park H, Merrill AH Jr, van Echten-Deckert G: Sphingosine 1-phosphate (S1P) lyase deficiency increases sphingolipid formation via recycling at the expense of de novo biosynthesis in neurons. J Biol Chem 2012;287:9128-9136.

70 Karaca I, Tamboli IY, Glebov K, Richter J, Fell LH, Grimm MO, Haupenthal VJ, Hartmann T, Gräler MH, van Echten-Deckert G, Walter J: Deficiency of sphingosine-1-phosphate lyase impairs lysosomal metabolism of the amyloid precursor protein. J Biol Chem 2014;289:16761-16772.

71 Jiang X, Han X: Characterization and direct quantitation of sphingoid base-1-phosphates from lipid extracts: A shotgun lipidomics approach. J Lipid Res 2006;47:1865-1873.

72 Borowsky AD, Bandhuvula P, Kumar A, Yoshinaga Y, Nefedov M, Fong LG, Zhang M, Baridon B, Dillard L, de Jong P, Young SG, West DB, Saba JD: Sphingosine-1-phosphate lyase expression in embryonic and adult murine tissues. J Lipid Res 2012;53:1920-1931.

73 Bektas M, Allende ML, Lee BG, Chen W, Amar MJ, Remaley AT, Saba JD, Proia RL: S1P lyase deficiency disrupts lipid homeostasis in liver. J Biol Chem 2010;285:10880-10889.

-74 Takasugi N, Sasaki T, Ebinuma I, Osawa S, Isshiki H, Takeo K, Tomita T, Iwatsubo T: FTY720/fingolimod, a sphingosine analogue, reduces amyloid-beta production in neurons. PLoS One 2013;8:e64050.

75 Asle-Rousta M, Kolahdooz Z, Oryan S, Ahmadiani A, Dargahi L: FTY720 (fingolimod) attenuates betaamyloid peptide (abeta42)-induced impairment of spatial learning and memory in rats. J Mol Neurosci 2013;50:524-532.

76 Hemmati F, Dargahi L, Nasoohi S, Omidbakhsh R, Mohamed Z, Chik Z, Naidu M, Ahmadiani A: Neurorestorative effect of FTY720 in a rat model of Alzheimer's disease: Comparison with memantine. Behav Brain Res 2013;252:415-421. 